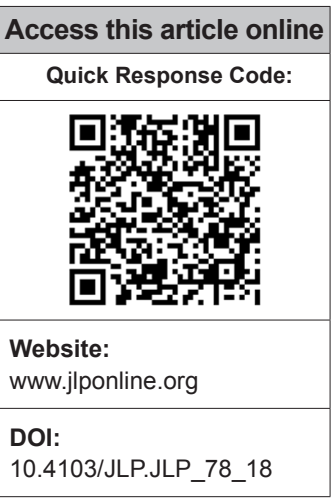

Departments of Laboratory Medicine and ${ }^{2}$ Orthopaedics, Jai Prakash Narayan Apex Trauma Centre, All India Institute of Medical Sciences, ${ }^{1}$ Division of

Trauma Surgery and Critical Care, Jai Prakash Narayan Apex Trauma Centre, All India Institute of Medical Sciences, New Delhi, India

Address for correspondence:

Dr. Purva Mathur,

Department of Laboratory Medicine, Jai Prakash Narayan Apex Trauma Centre, All India Institute of Medical Sciences, New Delhi - 110 029, India.

E-mail: purvamathur@ yahoo.co.in

Submission: 05-06-2018 Accepted: 05-08-2018

\section{Prevalence, etiology, and antibiotic resistance profiles of bacterial bloodstream infections in a tertiary care hospital in Northern India: A 4-year study}

\author{
Surbhi Khurana, Nidhi Bhardwaj, Minu Kumari', Rajesh Malhotra², Purva Mathur
}

\begin{abstract}
:
INTRODUCTION: Bloodstream infections (BSIs) can lead to life-threatening sepsis and are globally associated with high morbidity and mortality. Although BSIs require immediate antimicrobial treatment, their prevalence, etiology, and antimicrobial susceptibilities differ from one country to other. There is a dearth of such data from India. Here, we report the 4-year etiologic data on BSI in trauma patients admitted to a tertiary care referral hospital in New Delhi, India.
\end{abstract}

MATERIALS AND METHODS: A retrospective study was conducted the trauma center between January 2013 and December 2016. The routine microbiological data on bacterial BSI were recorded and determined retrospectively from the laboratory records. Antimicrobial susceptibility profiles were statistically analyzed.

RESULTS: A total of 2017 bacterial strains isolated from blood culture samples were included for microbiological analysis. During the study, the median age of the patients varied from 30 to 35 years, with the percentage of females in the study population varying from $17 \%$ to $19 \%$. The predominant pathogens were Gram-negative bacteria, with Acinetobacter species, followed by Klebsiella species being the most commonly isolated organisms throughout the 4 years of study. Among Gram-positive isolates, Staphylococcus species were the leading pathogens (11\%-15\%).

CONCLUSIONS: A detailed analysis of prevalence, etiology of BSIs in India and its resistance profile is crucial for appropriate antibiotic use, clinical management, and formulation of antibiotic policies and preventive measures.

Key words:

Antimicrobial profile, blood stream infections, etiology, Gram-negative bacteria, Gram-positive bacteria, trauma patients

\section{Introduction}

Bloodstream infections (BSIs) range from self-limiting infections to life-threatening sepsis and are an important cause of sepsis-related morbidity and mortality worldwide. ${ }^{[1]}$ Studies have revealed that the annual numbers of BSI episodes ranged from 1,213,460 to 1,381,590 in Europe and

This is an open access journal, and articles are distributed under the terms of the Creative Commons Attribution-NonCommercial-ShareAlike 4.0 License, which allows others to remix, tweak, and build upon the work non-commercially, as long as appropriate credit is given and the new creations are licensed under the identical terms.

For reprints contact: reprints@medknow.com
575.462-677.389 in North America with large annual numbers of BSI-associated deaths. ${ }^{[2]}$ In a developed setting, the inhospital mortality rates are observed to be at least $40 \% \cdot{ }^{[3]}$ Data on the profile of BSI from low- and middle-income countries like India are limited. ${ }^{[4]}$

The epidemiology and pathogen profile of BSIs vary between regions. ${ }^{[5]}$ This

How to cite this article: Khurana $S$, Bhardwaj N, Kumari M, Malhotra R, Mathur P. Prevalence, etiology, and antibiotic resistance profiles of bacterial bloodstream infections in a tertiary care hospital in Northern India: A 4-year study. J Lab Physicians 2018;10:426-31. 
considerable unevenness between hospitals and health-care centers in different countries requires constant analysis of local trends. Many bacterial pathogens have developed resistance to most of the antibiotics and are creating a serious health crisis with many economic and social inferences all over the worlds. ${ }^{[6]}$

The changing epidemiology and susceptibility patterns of microorganisms in India threaten the effectiveness of most, if not all; antibiotics frequently used to prevent and treat bacterial infections. ${ }^{[7]}$ In addition to the increasing resistance to even the last resort drugs such as colistin from across the globe, the situation is getting graver because of the absence of any new drugs in the pipeline. ${ }^{[8,9]}$

There is a dearth of detailed studies and data on prevalence, etiology, and antibiotic resistance profiles of bacterial BSIs in India. Such data are crucial for enabling clinicians to improve the empirical treatment and administer appropriate antimicrobial therapy. In addition, it is vital to recognize and track the source of all BSIs to prioritize and implement preventive measures.

India is a developing economy and a hotspot for emerging infectious diseases. Rates of antibiotic resistance, an important reason of treatment failure and subsequent mortality are also alarming in India. However, the epidemiology of BSI in Indian adults is not well studied and thus requires constant surveillance of bloodstream infections.

With this background, the present study was conducted to analyze various organisms causing BSI and their prevalence and antibiotic resistance pattern, which would ultimately aid in decreasing the hospital stay and cost of treatment which would consequently reduce mortality. This article reports a 4-year retrospective analysis of BSI data at a tertiary referral center in India.

\section{Materials and Methods}

\section{Study design and data collection}

This is a retrospective, cohort study of patients with bacterial BSI admitted to our tertiary care trauma center between January 1, 2013, and December 31, 2016.

Our trauma center is a 186-bedded tertiary referral center. As a result, the hospital receives patients both directly from the community and transferred from hospitals in the region. The study was approved by the local Institute Ethics Committee. All positive blood cultures with recognized bacterial pathogens among patients who were hospitalized during the study were included in the study. The routine microbiological profile was recorded for all the clinical samples received in the laboratory.

Blood samples were sent in BacTAlert (BioMérieux, France) bottles upon clinical suspicion of BSI. Bottles that signaled positive were then subculture on blood, MacConkey, and chocolate agar. These plates were incubated aerobically at $37^{\circ} \mathrm{C}$ and examined after 18-24 h. Bacterial identification was done by the Vitek II system. Antimicrobial susceptibility was done by Vitek II and disc diffusion technique as per Clinical and Laboratory Standards Institute (CLSI) guidelines. For Gram-negative isolates, disc diffusion testing was performed for the following antimicrobials for each isolate: Amikacin $(30 \mu \mathrm{g})$, cefepime $(30 \mu \mathrm{g})$, cefoperazone/sulbactam $(75 / 30 \mu \mathrm{g})$, cefoxitin $(30 \mu \mathrm{g})$, ceftazidime $(30 \mu \mathrm{g})$, chloramphenicol $(30 \mu \mathrm{g})$, ciprofloxacin $(5 \mu \mathrm{g})$, imipenem $(10 \mu \mathrm{g})$, netilmicin $(30 \mu \mathrm{g})$, piperacillin/tazobactam $(100 \mu \mathrm{g} / 10 \mu \mathrm{g})$, tigecycline $(15 \mu \mathrm{g})$, and trimethoprim-sulfamethoxazole $(1.25 / 23.75 \mu \mathrm{g})$. For Gram-positive isolates, disc diffusion testing was performed for the following antimicrobials for each isolate: amikacin $(30 \mu \mathrm{g})$, amoxicillin $(20 \mu \mathrm{g})$, amoxicillin/clavulanic acid $(20 / 10 \mu \mathrm{g})$, ampicillin $(10 \mu \mathrm{g})$, ampicillin/sulbactam $10 / 10 \mu \mathrm{g})$, cefoxitin $(30 \mu \mathrm{g})$, ciprofloxacin $(5 \mu \mathrm{g})$, clindamycin $(2 \mu \mathrm{g})$, colistin $(10 \mu \mathrm{g})$, co-trimoxazole $(1.25 / 23.75 \mu \mathrm{g})$, erythromycin $(15 \mu \mathrm{g})$, gentamicin $(10 \mu \mathrm{g})$, Levofloxacin $(5 \mu \mathrm{g})$, linezolid $(30 \mu \mathrm{g})$, Netilmicin (30 $\mu \mathrm{g})$, Nitrofurantoin $(30 \mu \mathrm{g})$, Oxacillin $(1 \mu \mathrm{g})$, Penicillin (10 U), Rifampicin $(30 \mu \mathrm{g})$, Teicoplanin $(30 \mu \mathrm{g})$, Tetracycline $(30 \mu \mathrm{g})$, and Vancomycin $(30 \mu \mathrm{g})$. Antibiotic susceptibilities were performed using CLSI guidelines with breakpoints from 2017. ${ }^{[10]}$

\section{Data entry and statistical analysis}

Data were entered into an indigenously developed automated surveillance system and analyzed using Stata/SE 12.1 (Stata Corp, LP, USA). In cases where there were multiple blood cultures positive with the same pathogen, only the $1^{\text {st }}$ positive blood culture was included in this study. Standard descriptive statistics were calculated for categorical (in percentage) and continuous variables (median and interquartile, interquartile range). $P$ value was calculated using Chi-square test for a row-by-column contingency table with appropriate degrees of freedom. $P<0.05$ was considered statistically significant.

\section{Results}

\section{Study population's demographics}

After exclusion of blood cultures positive with contaminants, as per standard definitions, 1983 positive bacterial blood cultures were recorded between January 2013 and December 2016, from which a total of 2017 bacteria were isolated. 
The median age of the patients varied from 30 to 35 years, with the percentage of females in the study population being $17 \%-19 \%$ [Table 1]. The range of patient-age largely lied between 24 and 54 years during the study. Among the 1983 positive blood samples 1009 (51\%), $902(45 \%), 17(1 \%), 23(1 \%)$, and $32(2 \%)$, were recovered respectively from surgical Intensive Care Units (ICUs), neurosurgical ICUs, orthopedic ICUs, emergency department, and follow-up outpatients.

\section{Analysis of microbiological dataset}

During the 4-year study, a total of 1983 blood samples of BSI patients were received in the laboratory, and more than one bacterium were isolated from $1.5 \%$ (29/1983) of these blood samples. A total of 2017 bacterial isolates were identified with $82 \%(1646 / 2017)$ with Gram-negative bacteria isolated and 18\% (371/2012) Gram-positive bacteria. Gram-negative bacteria were the most common cause of bloodstream infection in adults presenting to our tertiary referral hospital during all 4 years $(78 \%-85 \%)$. Acinetobacter species was the most commonly isolated bacteria in 2013, 2015, and 2016. Enterobacteriaceae were the most commonly isolated group of organisms among the study cases in all the 4 years except for 2014, when $26 \%$ of the total isolated bacteria were Burkholderia spp. This was a part of an outbreak (under publication). The predominant Enterobacteriaceae was Klebsiella spp. throughout the study, followed by Escherichia coli and Serratia spp in 2013 and 2015 and 2014 and 2016 respectively. Nonenterobacteriaceae were observed to be $43 \%-58 \%$ of the total bacteria isolated during the study period. Among Gram-positive isolates, Staphylococcus species were the leading pathogen $(11 \%-15 \%)$, followed by Enterococcus spp. $(4 \%-7 \%)$ [Table 2].

Tables 3 and 4 display the rates of antibiotic resistance of Gram-negative and Gram-positive isolates. Very high levels of antibiotic resistance were seen across all genera of family Enterobacteriaceae which was found to be statistically significant for all the antimicrobials tested. Similar trends were observed among the nonEnterobacteriaceae [Table 3]. Discordant resistant profiles between disc diffusion and Vitek II were obtained with colistin (results not reported here). Statistically significant antibiotic resistance to amoxicillin-clavulanic acid $(P<0.000)$, ampicillin $(P=0.021)$, clindamycin $(P=0.035)$, co-trimoxazole $(P=0.005)$, gentamicin $(P<0.000)$, levofloxacin $(P=0.006)$, oxacillin $(P<0.000)$, penicillin $(P=0.001)$, and rifampicin $(P=0.001)$ was observed among Gram-positive bacteria [Table 4].

\section{Discussion}

Among all types of nosocomial infections, BSIs prove to be potentially the most grave and expensive. Patients admitted to ICUs have an even higher risk of nosocomial
Table 1: Characteristics of the clinical study population

\begin{tabular}{lcccc}
\hline & \multicolumn{4}{c}{ Year } \\
\cline { 2 - 5 } & 2013 & 2014 & 2015 & 2016 \\
\hline Total, $n(\%)$ & 459 & 621 & 406 & 497 \\
Age, median (IQR) & $30(24-43)$ & $30(25-54)$ & $35(25-50)$ & $31(23-45)$ \\
Female sex, $n(\%)$ & $80(17)$ & $105(17)$ & $77(19)$ & $84(17)$ \\
Surgical ICUs, $n(\%)$ & $188(41)$ & $215(35)$ & $263(65)$ & $343(69)$ \\
Neurosurgical ICUs, & $248(54)$ & $392(63)$ & $134(33)$ & $128(26)$ \\
$n(\%)$ & & & & \\
Orthopedic ICUs, $n(\%)$ & $12(3)$ & 0 & $2(0.5)$ & $3(0.6)$ \\
Emergency department, & $4(0.9)$ & $8(1.3)$ & $4(1)$ & $15(3)$ \\
$n(\%)$ & & & & \\
Follow-up OPDs, $n(\%)$ & $7(1.5)$ & $6(1)$ & $3(0.7)$ & $8(2)$ \\
\hline
\end{tabular}

IQR $=$ Interquartile range, ICUs = Intensive Care Units, OPDs = Outpatient departments

Table 2: Etiology of bacterial bloodstream infections

\begin{tabular}{|c|c|c|c|c|}
\hline Pathogen & $\begin{array}{c}2013 \\
(n=484) \\
n(\%)\end{array}$ & $\begin{array}{c}2014 \\
(n=621) \\
n(\%)\end{array}$ & $\begin{array}{c}2015 \\
(n=411) \\
n(\%)\end{array}$ & $\begin{array}{c}2016 \\
(n=501) \\
n(\%)\end{array}$ \\
\hline \multicolumn{5}{|l|}{ Gram-negative isolates } \\
\hline \multicolumn{5}{|l|}{ Enterobacteriaceae } \\
\hline Enterobacter species & $11(2)$ & $13(2)$ & 0 & $5(1)$ \\
\hline Escherichia coli & $24(5)$ & $25(4)$ & $28(7)$ & $26(5)$ \\
\hline Klebsiella species & $51(11)$ & $50(8)$ & $101(25)$ & $106(21)$ \\
\hline Proteus species & $4(0.8)$ & $9(1)$ & $5(1)$ & $5(1)$ \\
\hline Providencia species & $10(2)$ & $13(2)$ & 0 & $3(0.6)$ \\
\hline Salmonella species & $6(1)$ & $6(1)$ & 0 & $13(2.5)$ \\
\hline Serratia species & $13(3)$ & $35(6)$ & 0 & $35(7)$ \\
\hline \multicolumn{5}{|l|}{ Non-Enterobacteriaceae } \\
\hline Acinetobacter species & $97(20)$ & $132(21)$ & $122(30)$ & $135(27)$ \\
\hline Aeromonas species & $1(0.2)$ & 0 & 0 & 0 \\
\hline Burkholderia species & $19(4)$ & $162(26)$ & $9(2)$ & $25(5)$ \\
\hline $\begin{array}{l}\text { Stenotrophomonas } \\
\text { species }\end{array}$ & $34(7)$ & $34(6)$ & $28(7)$ & $13(2.5)$ \\
\hline $\begin{array}{l}\text { Pseudomonas } \\
\text { aeruginosa }\end{array}$ & $87(18)$ & $30(5)$ & $40(8)$ & $38(8)$ \\
\hline $\begin{array}{l}\text { Other Gram-negative } \\
\text { bacteria }{ }^{\#}\end{array}$ & $19(4)$ & $19(3)$ & 0 & $5(1)$ \\
\hline \multicolumn{5}{|l|}{ Gram-positive isolates } \\
\hline Enterococcus species & $34(7)$ & $26(4)$ & $28(7)$ & $37(7)$ \\
\hline Staphylococcus species & $74(15)$ & $67(11)$ & $50(12)$ & $54(11)$ \\
\hline Streptococcus species & 0 & 0 & 0 & $1(0.2)$ \\
\hline
\end{tabular}

"Morganella species, Pantoea species, Achromobacterspecies, Chryseobacterium species, Elizabethkingia species, Ralstonia pickettii, Sphingomonas paucimobilis

BSIs than those admitted to other types of units. Although the causative agents are affected by a number of factors; predominantly the focus of infection, comorbidities such as chronic diseased conditions, immunodeficiency, other than geographic, socioeconomic and environmental factors, important insights can be gained from the analyses of the microbiological profile of BSIs as most cases reflect severe illness and the bacteria detected are usually the causative agents of the disease. The unprecedented antimicrobial resistance to antimicrobials like colistin has breached one of the last lines of defense against such infections with multidrug-resistant bugs. ${ }^{[9]}$ 


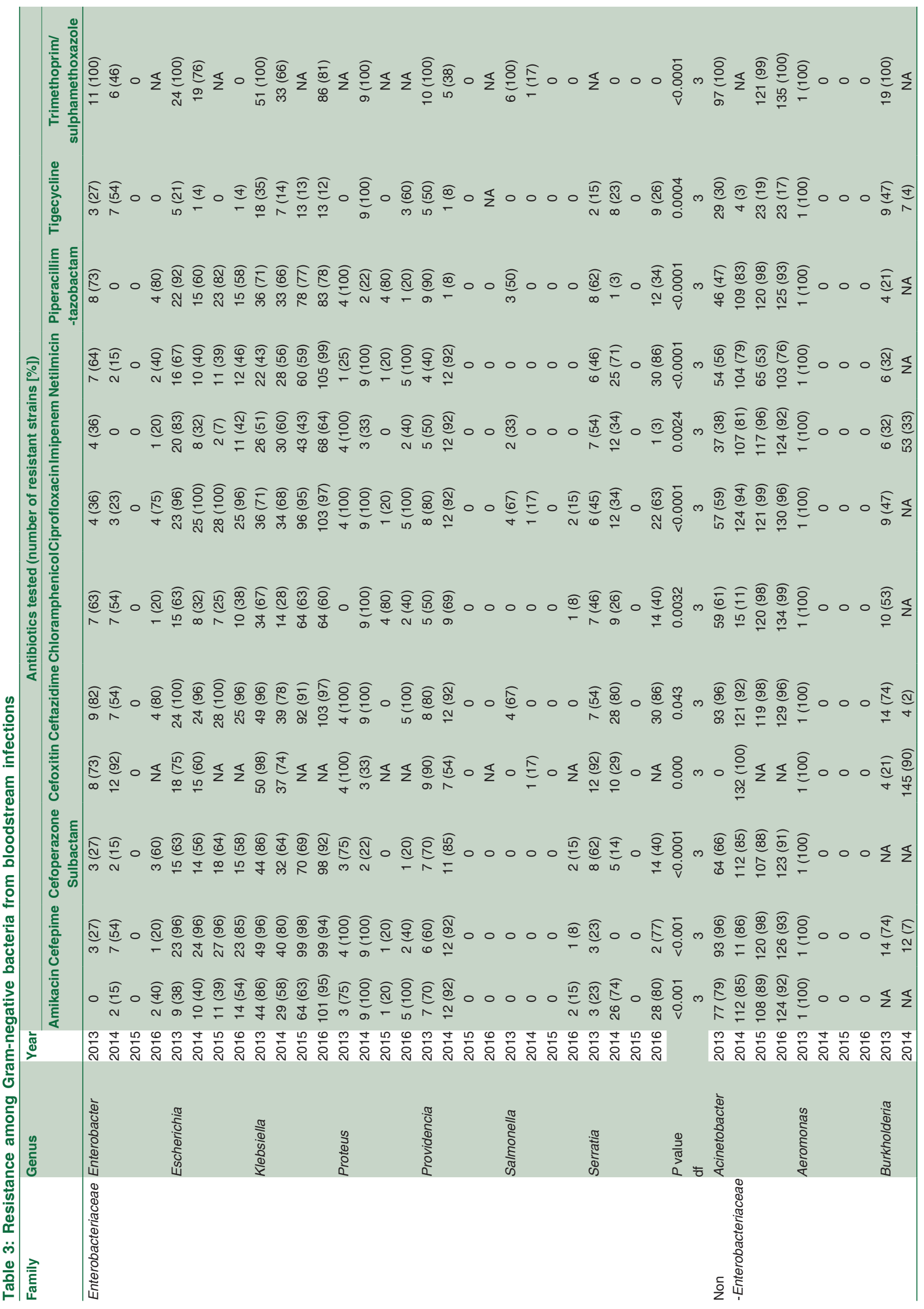



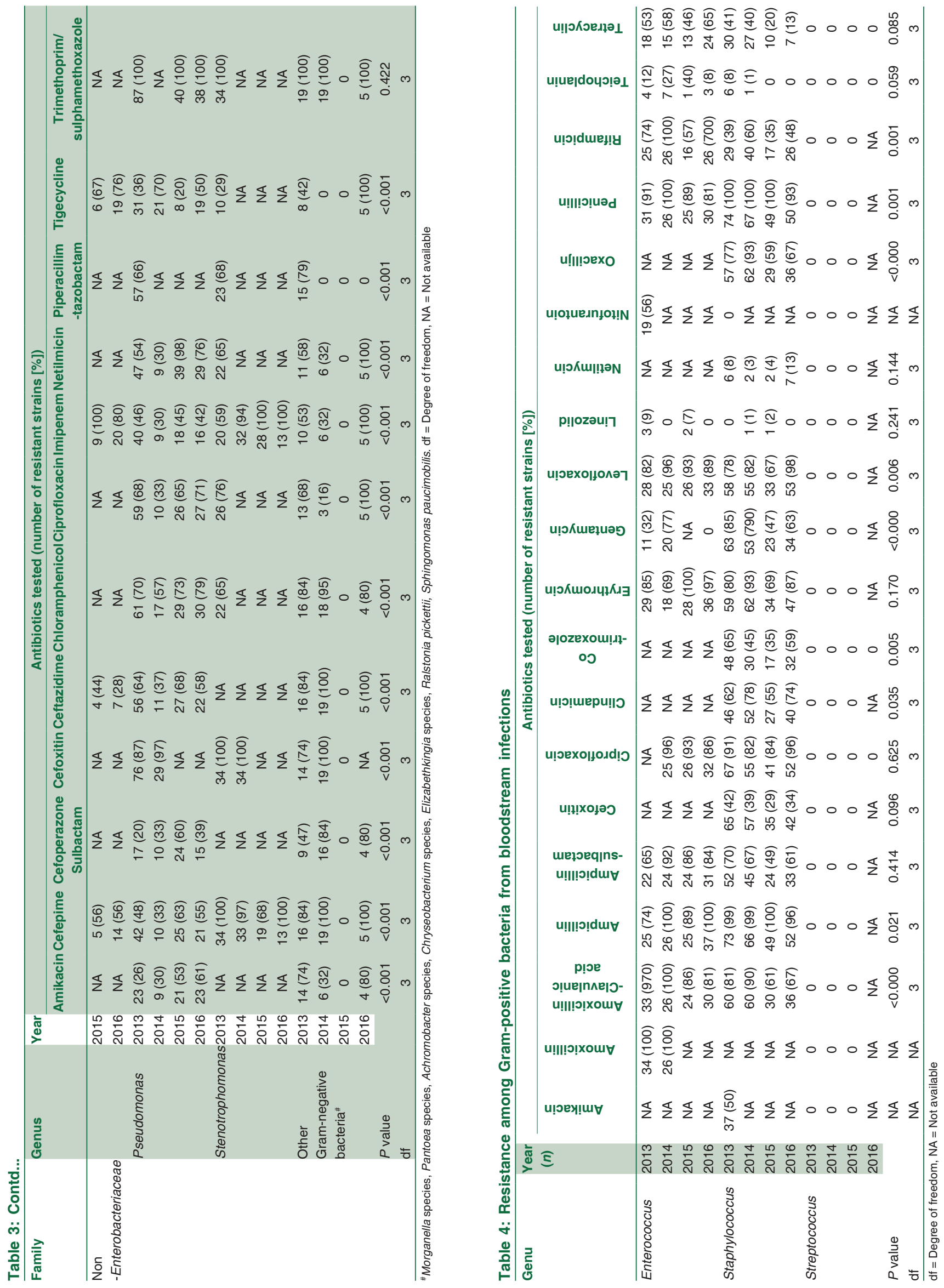
We observed a predominance of young and middle-aged adult males among patients with BSI (81\%-83\%). This phenomenon is similar to various studies reporting septic shock as one of the top causes of death. ${ }^{[4]}$ We observed a higher proportion of males than females. The highest percentage of patients with BSI in our study were from surgical and neurosurgical ICUs.

In a previous study from the same center conducted in 2011-2012 a high prevalence of BSIs was reported. We reported a total of 316 organisms isolated from the 296 episodes of BSIs. ${ }^{[1]}$ The numbers have only increased since then. Acinetobacter species followed by Klebsiella species are still the most common cause of BSI.

Gram-positive and Gram-negative bacteria showed very high resistance to most the antibiotics tested, and the statistical analysis clearly suggest that the drug resistance is undeniably significant and poses threat more-so to high-risk patients having blood culture positive.

Our study, however, has some important limitations. First, our trauma center is a tertiary referral hospital and specializes in trauma cases. Therefore, the pattern of etiology, resistance, and spectrum of clinical disease is different from that seen in other hospitals in India. Second, we have reported only the total number of organisms and not the BSI episodes. Study of BSI episodes classified into community- and hospital-acquired BSIs would have led to a more comprehensive analysis. Finally, the importance and role of certain bacteria, such as Aeromonas species or Stenotrophomonas species, which have been associated with both real and pseudobacteremia infection was not ascertained because of a lack of repeat sampling and the retrospective nature of our study.

Considering the load of BSI and the toll it is taking, especially on our young and middle-aged adult population, we are in dire need of rapid identification and antimicrobial susceptibility testing of the causative agents of bloodstream infections. Such point-of-care testing systems would promptly provide essential information to clinicians for selecting an appropriate antimicrobial therapy for patients with potentially fatal bloodstream infections. We have seen a positive impact of an intensive surveillance on the central line-associated bloodstream infections in a study conducted at our center emphasizing the need of regular and stringent surveillance of BSI. ${ }^{[12]}$ Thus, a deeper understanding of the prevalence, etiology of BSIs in India, its resistance patterns and their impact on patients' outcomes is important to guide clinical management and appropriate antibiotic use.

\section{Conclusion}

We require a detailed analysis of the prevalence and etiology of BSIs and its resistance profile. It will lead to appropriate antibiotic use, clinical management, and formulation of antibiotic policies and preventive measures.

\section{Financial support and sponsorship}

Nil.

\section{Conflicts of interest}

There are no conflicts of interest.

\section{References}

1. Abubakar II, Tillmann T, Banerjee A. Global, regional, and national age-sex specific all-cause and cause-specific mortality for 240 causes of death, 1990-2013: A systematic analysis for the Global Burden of Disease Study 2013. Lancet 2015;385:117-71.

2. Goto M, Al-Hasan MN. Overall burden of bloodstream infection and nosocomial bloodstream infection in North America and Europe. Clin Microbiol Infect 2013;19:501-9.

3. Laupland KB, Davies HD, Church DL, Louie TJ, Dool JS, Zygun DA, et al. Bloodstream infection-associated sepsis and septic shock in critically ill adults: A population-based study. Infection 2004;32:59-64.

4. Dat VQ, Vu HN, Nguyen The H, Nguyen HT, Hoang LB, $\mathrm{Vu}$ Tien Viet $\mathrm{D}$, et al. Bacterial bloodstream infections in a tertiary infectious diseases hospital in Northern Vietnam: Aetiology, drug resistance, and treatment outcome. BMC Infect Dis 2017;17:493.

5. Southeast Asia Infectious Disease Clinical Research Network. Causes and outcomes of sepsis in Southeast Asia: A multinational multicentre cross-sectional study. Lancet Glob Health 2017;5:e157-67.

6. Gohel K, Jojera A, Soni S, Gang S, Sabnis R, Desai M. Bacteriological profile and drug resistance patterns of blood culture isolates in a tertiary care nephrourology teaching institute. Biomed Res Int 2014;2014:153747.

7. Deasy J. Antibiotic resistance: The ongoing challenge for effective drug therapy. JAAPA 2009;22:18-22.

8. Khurana S, Mathur P, Kapil A, Valsan C, Behera B. Molecular epidemiology of beta-lactamase producing nosocomial gram-negative pathogens from North and South Indian hospitals. J Med Microbiol 2017;66:999-1004.

9. Liu YY, Wang Y, Walsh TR, Yi LX, Zhang R, Spencer J, et al. Emergence of plasmid-mediated colistin resistance mechanism MCR-1 in animals and human beings in China: A microbiological and molecular biological study. Lancet Infect Dis 2016;16:161-8.

10. Clinical and Laboratory Standards Institute. Performance Standards for Antimicrobial Susceptibility Testing; Twenty-Third Informational Supplement. CLSI Document M100-S27. Wayne: Clinical and Laboratory Standards Institute; 2017.

11. Mathur P, Varghese P, Tak V, Gunjiyal J, Lalwani S, Kumar S, et al. Epidemiology of blood stream infections at a level-1 trauma care center of india. J Lab Physicians 2014;6:22-7.

12. Tak V, Mathur P, Kumar S, Gupta B, Gupta A, Sinha S, et al. Impact of an intensive surveillance on central line associated blood stream infections at an Indian trauma center. J Patient Saf Infect Control. 2014;2:38-41. 